\title{
On Media
}

\author{
Why We Are Still Not Cognitive Psychologists: \\ A Review of Why I Am Not a Cognitive Psychologist: \\ A Tribute to B. F. Skinner \\ Brady J. Phelps \\ South Dakota State University
}

\begin{abstract}
Any instructor of behavior analysis is no doubt aware that neuroscience, characterized by a cognitive-mentalistic approach, has substantial influence in behavioral science. As a counterpoint, behavior analysis can raise timely questions and promote critical thinking, as did Skinner (1977) in his critical analysis of cognitive psychology. Keenan and Dillenburger (2004) have produced a CD-ROM with effective audio-visual presentations to aid in the teaching of behavior analysis and in critiquing reductionistic mentalism.

Key words: behavior analysis, B. F. Skinner, neuroscience, mentalism, reductionism, cognitive psychology
\end{abstract}

In his book, Soul Made Flesh: The Discovery of the Brain - and How It Changed the World, Zimmer (2004) speculated about the implications of nascent brain science at Oxford University in the 17th century:

These men of Oxford ushered in a new age, one in which we still live-call it the Neurocentric Age - in which the brain is central not only to the body but to our conception of ourselves. ... Today some three hundred forty years later, the Neurocentric Age is more deeply entrenched than ever. ... The maps that that neuroscientists make today are like the early charts of the New World with grotesque coastlines and blank interiors. (p. 7)

Are contemporary behavior analysts equipped to address the reductionism of today's brain-centered psychology? Keenan and Dillenburger (2004) make some unique inroads into this question with the CD-ROM Why I

I would like to acknowledge the helpful comments and suggestions from Charles Lyons and Jeffrey Weatherly on an earlier version of this paper as well as those of the reviewers.

Correspondence concerning this article should be addressed to Brady J. Phelps, Department of Psychology, South Dakota State University, Scobey Hall Box 504, Brookings, South Dakota 57007 (e-mail: Brady.Phelps@sdstate.edu).
Am Not a Cognitive Psychologist: A Tribute to B. F. Skinner. This Windows ${ }^{\circledR}$-based CD-ROM consists of three modules: Brain, Illusions, and Inside. The content of this CD-ROM is a unique presentation of behavior analysis; it is certainly not programmed instruction in the typical sense. The user can pick any of these modules at any time, and each of the modules have untitled chapters; the "proper" use of this teaching tool is not necessarily a linear sequence.

Keenan and Dillenburger make very creative use of atypical visual icons and video clips. Along with its audio commentary, this CD-ROM provides antecedents that set the occasion for critical thinking about reductionism. In doing so, the CDROM is an effective tutorial to show just how relevant Skinner (1977) is today and to shape students' behavior into the practice of asking critical questions about invoking the brain and mentalism to explain behavior. Why I Am Not a Cognitive Psychologist: A Tribute to B. F. Skinner does not make many arguments that are novel to most behavior analysts. It is not intended for the typical reader of The Behavior Analyst. Instead, the program is intended to be used in 
teaching and introducing behavior analysis to a novice audience, and it is a gem in this regard.

As any behavior analyst knows, Skinner and virtually all subsequent behavior analysts have taken an approach that differs from that of much of today's neuroscience in viewing how brain and behavior are related. Although a special issue of the Journal of the Experimental Analysis of Behavior devoted to the relation between behavior analysis and neuroscience only appeared in 2005, Skinner argued for decades about the need for parallel and complementary sciences of behavior and brain (Skinner, 1938, 1974; Timberlake, Schaal, \& Steinmetz, 2005). For a study of the brain to develop properly, it needs satisfactory protocols for the study of behavior (Richelle, 1993). In fulfillment of this view, operant techniques developed by Skinner in the "alleged black-box approach" (Richelle, p. 89) are now widely used by various brain sciences (Timberlake et al.). Nevertheless, cognitive psychologists (or cognitive scientists or cognitive neuroscientists) have generally taken a particular route in attempts to determine what is in the brain and what their models of the brain have to offer as explanatory accounts of behavior. Attempts to critique or question the type of neuroscience seen weekly in publications such as Science or Nature run the risk of making behavior analysis susceptible to the stereotype of behaviorism as considering the human brain or a person as a black box. Nevertheless, a critique of the common assumptions of cognitive neurosciences that points out what these sciences cannot answer or avoid addressing is not only possible but very revealing, and that is provided by the $\mathrm{CD}$ being reviewed. For reductionism to be valid, it must have something to reduce, (Bennett \& Hacker, 2003; Schlinger, 2006). Keenan and Dillenburger (2004) raise similar, thought-provoking questions about cognitive psychology, neuroscience, and mentalism in an audiovisual format that is user-accessible for a behavior analyst in training.

\section{Me and My Brain}

A great deal of the material offered by Keenan and Dillenburger goes into critiquing "mentalism," that is, the separation of events as being either mental or behavioral (Baum, 2005). The authors provide a video clip in which a young girl says "I have a brain" (a perfectly acceptable statement of fact) but then the video fades the girl out and fades in an image of a human brain while the same voice utters the same statement. A brain itself saying, "I have a brain," is a nonsense statement, but in the visual thought experiment presented by Kennan and Dillenburger, an example of what starts out as an acceptable and sensible statement transitions into a nonsensical statement. The episode raises the question of whether there is a point of transition from sensical to nonsensical and if so, where it is. The CD reinforces the reality that with regard to having a brain, there is only one entity, the whole person, that makes the statement sensible (Schlinger, 2005). The syntax and structure of everyday language, however, create the confusion of a duality of "me and my brain" when no such independent duality exists (Hineline, 1980).

The CD next presents video of a young girl and an elderly lady both being asked if they have a brain, how they know they have a brain given they have never seen it, what functions and actions their brain performs for them, what they themselves are doing while their brain remembers for them, calculates for them, and thinks for them. The point of the two exercises about the brain is that when the vernacular is introduced into accounts of behavior, illusions occur that can create the impression of dualities when none exist. When 
people are interviewed with a dualistic language, people are inclined to think and speak in dualistic terms. Behavioral scientists must be cognizant of the illusions inherent in a vernacular adopted into a formal language of explanation and wary for how any scientific inquiry can be misdirected by the mirages of language.

\section{If It Is Raining, Is It Also Thinking in My Head?}

Throughout the CD-ROM, Keenan and Dillenburger present either still images or brief video clips as thought-provoking antecedents to insightful audio commentary. The content is effectively tailored for the generation of college students who expect to be presented with visuals. Keenan and Dillenburger provide compelling arguments for the impact of out of the ordinary imagery to illustrate a scientific principle.

Consider the following three sentences: The wind is blowing; Memory is remembered; and $I t$ is raining. In the first two, the noun performing the action is implied by the action performed. There is no wind without the blowing; there is no memory in the absence of remembering. In the last, the noun performing the action is a nonexistent it. A more precise utterance would be to say that the rain is falling, but does that really clarify the sentence? The authors give lucid redefinition to the point being pursued: From the perspective of a science of behavior, reconsider the statement, "I have a brain." Without begging the question too much, what is the "I" that has the brain? The problem to be addressed here is that for each of the three sentences under initial analysis, it is implicitly understood what is meant, but the implications of such sentences are the real concern here. As Hineline stated, "Given that patterns of English virtually disavow actions without agents, when one describes an action that has no obvious external agent one gratuitously implies an agent. By convention, the implied agent is usually internal or mentalistic"' (1980, p. 81).

In a natural science, theorists search for general principles and descriptions about the natural world by observing events in the environment and describing and explaining these by relating the former to other natural events (Baum, 2005). If it is our use of language that has the potential to lead us off target in our search for laws of behavior, then our use of problematic language must be spotlighted with special attention. The advancement of any science dictates the shedding of vestigial concepts of past incorrect thinking, the exorcism of the unseen and putative causes of natural events (Baum). If one agrees with the foregoing, then are we still dealing with fictional its? Just because a language has a term for an it, does that instantly validate the reifying of the it in question?

\section{Looking Inside for It}

In a subsequent section of the CDROM, Keenan and Dillenburger present even more illusions borne out of the vernacular. In psychology's past, it was posited that a soul or a homunculus dwelled inside us, eventually being localized to the brain, and that this entity had the role of directing a person's action and thinking (Schlinger, 2005). The unrecognized illusions engendered by our language allowed this entity to become part of psychology and eventually reconceptualized as the mind, as Descartes" "thinking thing" (Schultz, 1981). As a separate entity within, its role was likewise to determine and direct the actions of the person; it became the mysterious it, the agent of action expressed by the behavior and body of the person so controlled (Schlinger, 2005). Now when a person's behavior changes, it is commonly said that the person has 
changed his or her mind or made up his or her mind. Although such a view is socially acceptable and a common convention of a vernacular, how do we begin to look for this agent, the mind, especially if it is a mere illusion borne out the vernacular? Moving the mind from the vernacular into an explanatory account of behavior poses the logical impossibility of trying to submit an entity that has no temporal or spatial referents into a scientific analysis (Chiesa, 1994). At a minimum, the subject of a scientific analysis must be localizable in time and space (Baum, 2005). When Keenan and Dillenburger use clever animations to show a brain uttering, "I have a mind" (or should it say, "I too have a mind!'), the familiarity and vacuousness of that statement become obvious. Ordinary language is not only a poor guide for the scientist but also clearly holds many illusions for the unsuspecting novice.

In an illustration of an analogy used by Skinner (1977), Keenan and Dillenburger present a video clip of a typical dry-cell battery being cut open to look for the electricity stored inside. Even though a detailed schematic can illustrate how electricity must be stored inside, examining the anatomy of the battery reveals nothing that looks like electricity. The analogy with the nervous system is apt; theorized schematics of a putative "conceptual nervous system" in the central nervous system reveal stored representations, memory, even an "executive," but examination of the actual central nervous system reveals only anatomy. A battery does not store electricity (Buckle, 2006) anymore than a nervous system stores experiences. Both a battery and the nervous system are changed in how they will respond by specific types of experiences (Skinner, 1985); the nervous system is changed by the selective action of environmental contingencies but any attempt to reify the change as storage or as an inner entity is unnecessary and likely mis- leading. The constructs of a conceptual nervous system do not match up well with the actual details of the central nervous system.

In an example that is closer to home for students of psychology, one mistake is all too common. In the course of respondent conditioning, when the conditioned response to the conditioned stimulus has been established, it is commonly said that the conditioned response is the result of an association having been formed between the conditioned stimulus and the unconditioned stimulus. But then some go one step too far and if asked to specify the details of this formed association, the typical response is that the organism has formed the association in question and that the association is inside the organism's nervous system. The proper answer is that the association is only in the experimenter's arrangement of the environmental contingencies or in the natural environment (Pierce \& Cheney, 2003). Of course, a change resulting from the association is a part of the now-altered nervous system (Skinner, 1985). Many students are resistant to this distinction and are quite adamant in insisting that the association must be inside the organism. Keenan and Dillenburger provide clever and creative visual antecedents with which to clarify the argument as to where to look for the association.

\section{An Archeological Dig for Word Origins}

Keenan and Dillenburger also provide valuable audio and video material for how to introduce the concepts of Skinner's (1989) chapter on the origins of cognitive thought. As Skinner elucidated, the terms now used to refer to feelings and cognitive processes typically began as references to specific aspects of behavior or to the contexts in which behavior occurred. Such terms slowly acquired a different connotation when they 
became the vocabulary for an it, the internal agent of action, the mind. To provoke discussion, Keenan and Dillenburger present video footage of a rat performing on a schedule of intermittent reinforcement and ask the viewer to try and arrive at his or her own tentative accounts of the animal's behavior. Does the rat behave the way it does because it has arrived at its own rule for schedule performance? Has it decided when it should press the lever? Does it have an expectancy to conform with to produce the reinforcer? With these and other possible inferences from the observed behavior, the viewer is asked if anything is gained by making such inferences rather than referring to a historical account of the animal's experience with the contingencies of a particular schedule of reinforcement. For useful levity, the viewer can click on a highlighted icon and see a "bubble" of speech wherein the rat says, "Those are your thoughts, not mine," to encourage the viewer to hesitate to fill the rat with the viewer's mentalistic speculations.

For another example, the authors provide a video clip of a young girl, initially being wobbly and unsteady starting out on her bicycle but quickly riding it with control and apparent confidence. If we try to account for her behavior change by concluding the rule or algorithm for bicycle riding came "on-line" after an initial search-delay or by citing the executive in her prefrontal cortex that processed the needed information, collated it with stored information from memory, rehearsed the action and then issued an output commandline to execute the desired action, is anything gained? With a list of constructs dwelling in a conceptual nervous system, do we gain anything except verbiage for the invented surrogates for the actual mechanism of behavior change, learning from experience how to balance, resulting from the child's history of experienc- ing the physical contingencies associated with riding a bicycle? Skinner noted the invention of such inner causes was to be expected with operant behavior: "By its very nature operant behavior encourages the invention of mental or cognitive processes said to initiate action. ... The behavior seems to start up suddenly, without advance notice as if spontaneously generated. Hence the invention of such cognitive entities as intention, purpose or will" (1977, p. 4). Keenan and Dillenburger give audio-visual means with which to let students see how quickly they will leap to invoking mental inventions as well as the means by which instructors can inject some degree of skepticism and critical thinking about the necessity for doing so.

\section{Futuring and Past-ing}

Keenan and Dillenburger, in a challenging module, also lead the listenerviewer in a discussion of anticipating futures ("futuring") and remembering pasts ("past-ing"). The question is posed: What are people actually doing when they are said to be seeing or anticipating their future as well as remembering and dwelling on their past? Keenan and Dillenburger describe people as engaged in "time traveling" and make the case that a very particular type of behavior is being performed when a person engages in these actions. Others have made similar points, viewing some remembering as a behavior akin to seeing. William Verplanck used the analogy of trying to remember very recent events versus distant events as comparable to trying to see objects that are in the same room with you, right in front of you, compared to trying to see objects 10 yards away, 50 yards away, or more. In both the literal seeing and in the attempt to see the past, one can clearly see more of the more proximate objects and events. The more distant an event or object, the more it is obscured by 
being too far away and by other events and objects in our line of sight. Keenan and Dillenburger make the point that any time engaged in anticipating and remembering constitutes activity in the present, in the now, and are acts of self-observation. Indeed, very recent neurobiological research indicates that the type of brain damage that will impair a person's ability to remember also compromises a person's ability to envision and anticipate likely upcoming events (Miller, 2007). Placing a person's behavior in its proper context requires a viewing of any present behavior as being a part of an ongoing behavioral stream; a person is an ongoing process, and a longitudinal study with $N=1$ is the proper research design rather than a series of snapshots composing a cross-sectional study. To make this point clearer, the authors use imaginative still images to present views of a person moving through a three-dimensional field of time and experiences. In a more typical flawed and segmented cross-sectional view of a person, mentalistic events are inferred as occurring inside the person's head and are used to explain the behavior in question. Just as when an analogueformat film loses its coherence when viewed frame by frame, any view of a person as a brief sample of behavior instead of a longitudinal view loses its coherence. Keenan and Dillenburger provide very cogent imagery and narrative to make their points about "futuring and past-ing" very lucid.

But in the vernacular, many accounts of behavior are "explained" by being a function of future events. Any expectancy, anticipation, or thought of a future are, however, activities that are occurring now. To paraphrase Keenan and Dillenburger, how these thoughts or expectations take the form they do in our present is a question about behavior itself that needs to be answered, not an explanation for the behavior observed. Any account of such be- havior (i.e., expecting, thinking) in a natural science cannot resort to explanatory fictions or surrogates of behavior and experiences (Baum, 2005); a complete account of such behavior must refer to functional relations between changes in the environment, internal or external, and subsequent changes in the behavior of the individual in question, whether the behavior is covert or overt (Keenan \& Dillenburger). If I were to make a prediction of some particular behavior being a function of a future event and subsequently see a verification of my prediction, the act of making the prediction should be the subject of study and not merely taken as an adequate account of the behavior and its relation to the future event. If I make a prediction about my upcoming behavior and attribute any subsequent behavior change to what will be in my mind at some future point, it calls for examination of my predictive verbal behavior occurring in the present, which presumably I learned from my past. What may be referred to as my "mind" or my "consciousness" and the apparent observed contents therein are behaviors occurring now and are more a function of my history rather than of mental events transpiring now (Schlinger, 2006).

\section{The "How" versus the "Why" of Behavior Change}

Keenan and Dillenburger subsequently present a short video clip of a chicken's behavior being shaped to turn in a left circle under the stimulus control of the printed letters "left" on a small sign. A behavior analyst would say that the chicken's behavior is under the control of the visual stimulus, but others might say the chicken behaves the way it does because it is reading the word, just as a person does. This lay conclusion is especially likely in the absence of an historical account of the contin- 
gencies that led to the pattern of behavior. Skinner put it this way: "Behavior is internalized as mental life when it is too slight to be observed by others, when we say it is covert" (1977, p. 3). Without the longitudinal observation of the chicken, a mental explanation is invented, and the chicken is reading the word and behaving according to what the word means. Palmer (2001) made the behavioral point of view clear by saying, "behavioral phenomena embraced by the term 'cognition' are distinctive in that commonly some portion of the performance is unobserved, and that portion that is observed is often insufficient to permit prediction or control. Appropriate behavior appears as if by magic" (p. 43).

But in the present context, if reading does not explain the behavior of the chicken in question, then perhaps the nervous system of the chicken does. Keenan and Dillenburger present a still image of a chicken brain and pose difficult questions: At what level of detailed examination of the brain of the chicken would we arrive at a more complete account of the observed behavior? Would a thorough enough understanding of the brain of a chicken with the behavior observed lead to a technology whereby another subject could be induced to demonstrate the same behavior change? Keenan and Dillenburger make the point decisively: Looking inside the brain of a subject offers the promise of identifying neurophysiological changes produced by environmental contingencies. The physiological changes are part of the changes in the dependent variable, the behavior of the subject, that occur as a function of the manipulation of the environmental independent variables. The changes that occur in the now-altered nervous system of the subject as a result of learning constitute the changed organism caused by the effects of the environment on the organism. The brain sciences study these changes in the nervous system but do not fully explain these changes; arguing otherwise results in a circular argument that leads us nowhere in identifying the underlying causes of behavior (Keenan \& Dillenburger). Any study of the brain is a worthwhile endeavor and an informative account of behavior at a different level of analysis. But the data from a science of the brain can obscure a more detailed and holistic view of a person as an ongoing process. The changes in the brain are part of the "how" of behavior and behavior change but not the "why" of behavior and behavior change; "When we attribute behavior to a neural or mental event, real or conceptual, we are likely to forget that we still have the task of accounting for the neural or mental event" (Skinner, 1984, p. 518). A view of the brain as the entity that controls us brings to mind an analogy with symbiosis. Cognitive neuroscientists come close to painting a picture of the person as having formed a symbiotic relationship with another organism, the brain. Cognitive accounts of the abilities and functions of the brain read as though humans provide a brain with a body, sensory organs, mobility, and defenses, and the brain provides the human with the complexity of behavior such as cognition, perception, command, and control. Attributing the behavior of an intact person to a brain by itself is known as the mereological fallacy (Bennett \& Hacker, 2003). Woodbridge (1965) put it this way: "We may be convinced that without brains we could not think, but to expect a brain to think seems to be about as unreasonable an expectation as one can entertain" (p. 183). Contrasted with the caricature of behaviorism as black-box brain theory, it is as if cognitive brain science sees a person as the host organism for the brain. Put in this context, can the cognitive neuroscience view of biology and a person's behavior be seen as holistic 
and appealing? Keenan and Dillenburger make a strong case for how to pull back the curtain to reveal that the wizard and his magic are not really there.

\section{Views of the Inside from Outside the Person}

Keenan and Dillenburger use atypical video imagery to present an imaginary scientific brain imagingmeasuring scanner that will let us see whatever amount and type of brain activity we wish. This scanner will let us plot functional relations between brain-activity changes as they occur in real time in response to environmental contingencies. From this plot, one can determine that changes in brain function at any specific point in time are a function of the environmental contingencies. But any data collected in this way constitute data that require a third-person perspective. Can the person whose behavior is monitored learn much about what controls his or her behavior from the scans of environment-brain-behavior relations? Yes, but only by stepping back and viewing the scans from the perspective of being outside one's self, as an observer. The point being made here is one that Skinner made repeatedly, that knowledge of the self results from the perspective of another person.

In arranging conditions under which a person describes the public or private world in which he lives, a community generates that very special form of behavior called knowing. ... Self-knowledge is of social origin. It is only when a person's private world becomes important to others that it is made important to him. It then enters into the control of the behavior called knowing. But self-knowledge has a special value to the individual himself. A person who has been "made aware of himself" by the questions he has been asked is in a better position to predict and control his own behavior. (1974, p. 31)

To illustrate the point of selfknowledge arising from a social environment, Keenan and Dillenburger present video footage of a person walking down a city street. The view of the street is from the perspective of the person himself as well as a view from the perspective of another observer. The latter perspective lets one see virtually everything the person walking sees as well as enabling a view of events the walking person cannot see. When the walker observes a bodily feeling and a subsequent change in behavior, the person may conclude that the feeling caused his or her behavior. By so doing, the person is committing the fallacy of false cause or post hoc ergo propter hoc. Merely noting the temporal arrangement of the feeling and behavior change and thereby concluding the former caused the latter is akin to concluding that the rooster's crowing caused the sun to rise (Schick \& Vaughn, 2004). By stepping back to view ourselves from the perspective of another, we become aware of events that give rise to feelings and thoughts and understand our own behavior more fully.

\section{The Use of Multimedia}

Much of this review is a paraphrasing of and commenting on the audio narration and visual images provided by Keenan and Dillenburger. The reader has been repeatedly asked to imagine seeing what the authors present visually with their CDROM. At first viewing, some may wonder exactly what is the relation between the still images and the video clips Keenan and Dillenburger selected to use and the topic being discussed. For instance, in their discussion of where the association formed in classical conditioning is, they present a still image of a dog, and if one clicks on the image, the dog opens its mouth and emits a lion's roar. How could this image be relevant to the issue of where association lies? The connection is not necessarily obvious unless the viewer "sees" the images presented as an occasion to ask him- or herself: What 
is being asked here and what have I, as a viewer-learner, typically thought about this topic? And have I ever stopped to examine my thinking on this topic? The atypical imagery can function so unexpectedly that it can make the viewer stop thinking and then begin to think about his or her thinking. When placed in the context of the perspective of a learner who will view the imagery with the mentalistic assumptions typical for an undergraduate psychology student, Keenan and Dillenburger have done very well to select atypical imagery with thoughtful narration to produce a very effective teaching tool. The section on debunking mentalism is first-rate behavior-analytic thinking and presents very thought-provoking imagery. The authors also have an exemplary tutorial on stimulus equivalence that will be a valuable introduction or addition to any lecture on that topic. This CD-ROM consists of three modules, with a complete audio transcript, to enable the use of each on discrete occasions, and each would serve well as a precursor to a discussion on several topics. It is designed to be used with either advanced undergraduate students or possibly 1st-year graduate students.

Could this CD-ROM be used by students on their own? Yes, for some graduate students; probably no, for undergraduates, if for no other reason than that the program is priced at approximately $\$ 100$ by its sole distributor in the United States, Insight Media. This CD-ROM is not a standard tutorial; instead it is an inventive treatment of a behavioranalytic view. It functioned to stimulate thinking akin to free association in this reviewer, as might be evident in the somewhat rambling nature of this review. Why I Am Not a Cognitive Psychologist: A Tribute to B. F. Skinner is a teaching gem. It deserves serious consideration in teaching of behavior analysis to the next generation. (For a preview of the
CD see http://www.celticfringe.me. $\mathrm{uk} /)$.

\section{REFERENCES}

Baum, W. M. (2005). Understanding behaviorism: Behavior, culture and evolution (2nd ed.). Malden, MA: Blackwell.

Bennett, M. R., \& Hacker, P. M. S. (2003). Philosophical foundations of neuroscience. Malden, MA: Blackwell.

Buckle, K. (2006, September). Ask the experts: How do batteries store and discharge electricity. Scientific American, p. 126.

Chiesa, M. (1994). Radical behaviorism: The philosophy and the science. Boston: Authors Cooperative.

Hineline, P. N. (1980). The language of behavior analysis: Its community, its functions, and its limitations. Behaviorism, 8, 67-86.

Keenan, M., \& Dillenburger, K. (2004). Why I am not a cognitive psychologist: A tribute to B. F. Skinner [CD-ROM] Celtic Fringe Productions. (Distributed by Insight Media, New York)

Miller, G. (2007, January 19). A surprising connection between memory and imagination. Science, 315, 312.

Palmer, D. C. (2001). Behavioral interpretation of cognition. History and Philosophy of Psychology, 3, 43-45.

Pierce, W. D., \& Cheney, C. D. (2003). Behavior analysis and learning (3rd ed.). Hillsdale, NJ: Erlbaum.

Richelle, M. N. (1993). B. F. Skinner: A reappraisal. Hillsdale, NJ: Erlbaum.

Schick, T., \& Vaughn, L. (2004). How to think about weird things: Critical thinking for a new age. Boston: McGraw Hill.

Schlinger, H. D. (2005). How the human got its mind. Skeptic, 11(4), 48-53.

Schlinger, H. D. (2006, May). Why consciousness hasn't been explained until now. Paper presented at the annual meeting of the Association for Behavior Analysis, Atlanta.

Schultz, D. (1981). A history of modern psychology (3rd ed.). New York: Academic Press.

Skinner, B. F. (1938). The behavior of organisms: An experimental approach. New York: Appleton-Century-Crofts.

Skinner, B. F. (1974). About behaviorism. New York: Knopf.

Skinner, B. F. (1977). Why I am not a cognitive psychologist. Behaviorism, 5, 1-10.

Skinner, B. F. (1984). Methods and theories in the experimental analysis of behavior. $\mathrm{Be}$ havioral and Brain Sciences, 7, 511-546, 541-546.

Skinner, B. F. (1985). Cognitive science and behaviorism. British Journal of Psychology, 76, 291-301.

Skinner, B. F. (1989). Recent issues in the analysis of behavior. Columbus, OH: Merrill. 
Timberlake, W., Schaal, D. W., \& Steinmetz, J. E. (2005). Relating behavior and neuroscience: Introduction and synopsis. Journal of the Experimental Analysis of Behavior, 84, 305-311.
Woodbridge, F. J. E. (1965). Nature and mind. New York: Russell \& Russell.

Zimmer, C. (2004). Soul made flesh: The discovery of the brain - and how it changed the world. New York: Free Press. 